\title{
New perspectives on human multitasking
}

\author{
Edita Poljac $^{1}\left[\right.$ [ $\cdot$ Andrea Kiesel $^{1} \cdot$ Iring Koch ${ }^{2} \cdot$ Hermann Müller $^{3}$
}

Received: 18 December 2017 / Accepted: 2 January 2018 / Published online: 18 January 2018

c) Springer-Verlag GmbH Germany, part of Springer Nature 2018

\section{Introduction}

Doing several things at the same time is an ability humans often rely on in their daily lives without truly giving it too much of notice. Scientific research, however, has informed us that this ability is all but a given, revealing its rather complex nature over the past years. Investigating the topic of human multitasking brings its own challenges, such as finding a proper way to specify what is meant by the term 'task', which is obviously a critical element for properly defining what is meant by 'multi-tasks'. Here, we define multitasking as a condition in which cognitive processes belonging to two or more tasks overlap in time (c.f., Koch et al., 2017). Such a broad definition of multitasking is clearly beneficial as it includes a relatively wide range of research paradigms, such as those used to investigate dual tasking (for review see Pashler, 2000) and task switching (for review see Kiesel et al., 2010; Monsell, 2003; Vandierendonck, Liefooghe, \& Verbruggen, 2010). The challenge, however, becomes evident when trying to investigate more complex (i.e., hierarchical or multi-step) tasks, for which one can question the level at which the actual tasks take place.

Despite such fundamental challenges, the endeavour of scientific disciplines focusing on this topic has been fruitful in terms of the knowledge gained. For instance, we now know that multitasking is typically accompanied with performance decrements that become evident when comparing performance on a task done in isolation to its performance done in combination with other tasks (e.g., Jiang, Saxe, \& Kanwisher, 2004; Poljac, Koch, \& Bekkering, 2009; Rubin \& Meiran, 2005; Sigman \& Dehaene, 2006). We also know that multitasking costs are modulated by different factors, such as for instance, by the time offered for

Edita Poljac

edita.poljac@gmail.com

1 University of Freiburg, Freiburg, Germany

2 RWTH Aachen University, Aachen, Germany

3 University of Giessen, Giessen, Germany the tasks to be prepared (Altmann, 2004; Hoffmann, Kiesel, \& Sebald, 2003; Koch, 2001; Meiran, 1996; Poljac, de Haan, van Galen, 2006) or by task order (Hirsch, Nolden, \& Koch, 2017; Luria \& Meiran, 2003; Szameitat, Lepsien, von Cramon, Sterr, \& Schubert, 2006; Töllner, Strobach, Schubert, \& Müller, 2012). In addition to these examples of task-related factors, the field has informed us that also individual differences play a critical role, such as age (Cepeda, Kramer, \& Gonzalez de Sather, 2001; Kray \& Ferdinand, 2014; Maquestiaux, Hartley, \& Bertsch, 2004; Reimers \& Maylor, 2005) or one's own individual multitasking style (Lehle \& Huebner, 2009; Miller, Ulrich, \& Rolke, 2009; Reissland \& Manzey, 2016).

Our understanding of cognitive processes behind multitasking has clearly improved over the years. This enhancement of knowledge in itself creates, however, an additional challenge: how to make sure that knowledge gained from disciplines having different research traditions is being shared and integrated. Although this challenge is not specific for multitasking research field, it is nevertheless an important one to address, as knowledge integration is per definition expected to serve as a catalyst for a better understanding of the topic. Luckily, the efforts have already been made to support integration of knowledge about multitasking. In fact, the current special issue is inspired by one such effort between cognitive and movement sciences, which is among the main aims of the recent Priority Project on Multitasking (SPP 1772) supported by the German Research Foundation (Deutsche Forschungsgemeinschaft, DFG). The current special issue is one of the products of this DFG funded Priority Project.

\section{Organisation of the special issue}

This special issue of the Psychological Research contains papers written by researchers actively involved in and contributing to the field of multitasking. The 19 papers included here reflect the diversity of approaches and methods typically employed in the field. Three of the papers have a 
theoretical focus. Two of them are integrative in nature, offering new perspectives by combining existing traditions of different research fields: one addressing a fundamental challenge of how to define a 'task' from the ideomotor perspective (Künzell et al.), and the other putting forward a new approach to multitasking motivated by ideas coming from judgment and decision-making research field (Bröker et al.). The third theoretical paper focuses on the mechanisms of interference control (Katzir et al.), in which the authors further examine the specificity of inhibition of task elements in task switching by implementing a theoretical analysis combined with a re-analysis of already published data.

All other papers in this special issue are empirical in nature. Most of them applied a version of well-established paradigms for testing multitasking, belonging to either dualtask (Kunde et al.; Kübler et al.; Künstler et al.; Langhanns \& Müller; Meijer \& Krampe; Pieczykolan \& Huestegge) or task-switching traditions (Arrington \& Braun; Aufschnaiter et al.; Brüning \& Manzey; Fintor et al.; Fröber et al.; Mittelstädt et al.; Olfers \& Band; Poljac et al.; Schuch et al.; Wendt et al.). Among these studies, we see creative, new ways of approaching the topic of multitasking. For instance, Kübler et al. introduce variations in task priority instructions to investigate task order regulation in dual tasking. Next, Arrington and Braun propose a novel, reward-based voluntary task switching paradigm (rVTS), in which they make one of the first attempts to investigate cognitive control mechanisms behind decision of task selection motivated by rewards. Another study in this special issue that also looks at how rewards influence performance on forced and freechoice task switching is by Fröber et al. Together, the two studies are already combining the traditions of task switching and decision-making, a way suggested to be fruitful for a better understanding of multitasking by the previously mentioned theoretical paper of Bröker et al.

Within the task-switching tradition, we see two more papers included in this special issue that introduce a novel methodological element, a task preview. While Mittelstädt et al. introduce a variable amount of the preview for nonchosen task stimuli to further investigate the typical observation of our tendency to repeat tasks more often than to switch tasks (i.e., repetition bias) in VTS paradigms, Brüning and Manzey use preview of tasks to investigate individual differences in multitasking strategies and their dependence on the risk of crosstalk between tasks. The topic of crosstalk is also addressed when investigating the control of cross-modal responses to a single stimulus (Pieczykolan \& Huestegge) and modality-compatibility benefits in task switching (Fintor et al.).

Along these lines of tasks influencing each other's performance during multitasking, Wendt et al. focus in their study on stimulus-related proactive interference during task switching. Furthermore, Schuch et al. look deeper into inhibitory control in task switching, more specifically into $N-2$ repetition costs and how these costs are modulated by action effects. Action effects are furthermore examined by Kunde et al. who are interested to see how visual action effects modulate dual-task performance. Related to action, but with a much more distinct motor component, interference is investigated by Langhanns and Müller, who measured brain activity by functional near-infrared spectroscopy (fNIRS) during cognitive-motor dual-task conditions. A combination of motor and cognitive tasks is furthermore used by Künstler et al., who examine how such a combination affects visual processing capacity.

Whereas most of the studies included in this special issue present behavioural data, brain activity was measured in one more study apart from Langhanns and Müller. Specifically, Olfers and Band used electroencephalogram (EEG) to register brain activity for the purpose of testing multitasking in terms of its malleability, investigating how game-based training modulates cognitive flexibility. Changes in multitasking ability are also addressed in two more studies that look at the effects of age, with Meijer and Krampe focusing on movement training and cognitive control in dual tasking and Poljac et al. on patterns of task choice in voluntary task switching. Finally, the exciting topic of time-based expectancies in multitasking is at the centre of the study done by Aufschnaiter et al., who are interested in how time-based expectancies of tasks affect task-switching behaviour.

Together, this special issue offers an overview of a wide range of research questions currently in the focus within the research field of multitasking, indicating where the field is heading at and presenting a set of new perspectives on human multitasking. As guest editors, we would like to thank the editor of the journal, the authors, and the reviewers for enabling us to create this Special Issue on 'New Perspectives on Human Multitasking'.

Edita Poljac Andrea Kiesel Iring Koch Herman Müller

Funding This study (editorial) was funded by the Deutsche Forschungsgemeinschaft (DFG), Grant number Ki1388-/7-1.

\section{Compliance with ethical standards}

Conflict of interest Edita Poljac declares that she has no conflict of interest. Andrea Kiesel declares that she has no conflict of interest. Iring Koch declares that he has no conflict of interest. Hermann Müller declares that he has no conflict of interest.

Ethical approval This article does not contain any studies with human participants or animals performed by any of the authors. 


\section{References}

Altmann, E. M. (2004). Advance preparation in task switching: What work is being done? Psychological Science, 15(9), 616-622. https://doi.org/10.1111/j.0956-7976.2004.00729.x.

Cepeda, N. J., Kramer, A. F., \& Gonzalez de Sather, J. C. (2001). Changes in executive control across the life span: Examination of task-switching performance. Developmental Psychology, 37(5), 715-730. https://doi.org/10.1037/0012-1649.37.5.715.

Hirsch, P., Nolden, S., \& Koch, I. (2017). Higher-order cognitive control in dual tasks: Evidence from task-pair switching. Journal of Experimental Psychology: Human Perception and Performance, 43(3), 569-580. https://doi.org/10.1037/xhp0000309.

Hoffmann, J., Kiesel, A., \& Sebald, A. (2003). Task switches under Go/ NoGo conditions and the decomposition of switch costs. European Journal of Cognitive Psychology, 15(1), 101-128. https:// doi.org/10.1080/09541440303602.

Jiang, Y., Saxe, R., \& Kanwisher, N. (2004). Functional magnetic resonance imaging provides new constraints on theories of the psychological refractory period. Psychological Science, 15, 390-396. https://doi.org/10.1111/j.0956-7976.2004.00690.x.

Kiesel, A., Steinhauser, M., Wendt, M., Falkenstein, M., Jost, K., Philipp, A. M., \& Koch, I. (2010). Control and interference in task switching-A review. Psychological Bulletin, 136(5), 849-874. https://doi.org/10.1037/a0019842.

Koch, I. (2001). Automatic and intentional activation of task sets. Journal of Experimental Psychology: Learning, Memory, \& Cognition, 27(6), 1474-1486. https://doi.org/10.1037//0278-7393.27.6.1474.

Koch, I., Poljac, E., Müller, H., \& Kiesel, A. (2017). Cognitive structure, flexibility, and plasticity in human multitasking - an integrative review of dual-task and task-switching research. Psychological Bulletin. (in press).

Kray, J., \& Ferdinand, N. K. (2014). Task switching and aging. In J. Grange \& G. Houghton (Eds.), Task switching and cognitive control (pp. 350-371). Oxford: Oxford University Press.

Lehle, C., \& Huebner, R. (2009). Strategic capacity sharing between two tasks: Evidence from tasks with the same and with different task sets. Psychological Research Psychologische Forschung, 73(5), 707-726. https://doi.org/10.1007/s00426-008-0162-6.

Luria, R., \& Meiran, N. (2003). Online order control in the psychological refractory period paradigm. Journal of Experimental Psychology: Human Perception \& Performance, 29(3), 556-574. https:// doi.org/10.1037/0096-1523.29.3.556.

Maquestiaux, F., Hartley, A. A., \& Bertsch, J. (2004). Can practice overcome age-related differences in the psychological refractory period effect? Psychology and Aging, 19(4), 649-667. https://doi. org/10.1037/0882-7974.19.4.649.

Meiran, N. (1996). Reconfiguration of processing mode prior to task performance. Journal of Experimental Psychology: Learning, Memory, \& Cognition, 22, 1423-1442. https://doi. org/10.1037//0278-7393.22.6.1423.
Miller, J., Ulrich, R., \& Rolke, B. (2009). On the optimality of serial and parallel processing in the psychological refractory period paradigm: Effects of the distribution of stimulus onset asynchronies. Cognitive Psychology, 58(3), 273-310. https://doi.org/10.1016/j. cogpsych.2006.08.003.

Monsell, S. (2003). Task switching. Trends in Cognitive Sciences, 7(3), 134-140. https://doi.org/10.1016/S1364-6613(03)00028-7.

Pashler, H. (2000). Task switching and multitask performance. In S. Monsell \& J. Driver (Eds.), Attention and Performance XVIII: Control of cognitive processes (pp. 277-307). Cambridge, MA: MIT Press.

Poljac, E., De Haan, A. D., \& Van Galen, G. P. V. (2006). Current task activation predicts general effects of advance preparation in task switching. Experimental Psychology, 53(4), 260-267. https://doi. org/10.1027/1618-3169.53.4.260.

Poljac, E., Koch, I., \& Bekkering, H. (2009). Dissociating restart costs and mixing costs in task switching. Psychological Research Psychologische Forschung, 73(3), 407-416. https://doi.org/10.1007/ s00426-008-0151-9.

Reimers, S., \& Maylor, E. A. (2005). Task switching across the life span: Effects of age on general and specific switch costs. Developmental Psychology, 41(4), 661-671. https://doi. org/10.1037/0012-1649.41.4.661.

Reissland, J., \& Manzey, D. (2016). Serial or overlapping processing in multitasking as individual preference: Effects of stimulus preview on task switching and concurrent dual-task performance. Acta Psychologica, 168, 27-40. https://doi.org/10.1016/j. actpsy.2016.04.010.

Rubin, O., \& Meiran, N. (2005). On the origins of the task mixing cost in the cuing task-switching paradigm. Experimental Psychology: Learning, Memory, and Cognition, 31(6), 1477-1491. https://doi. org/10.1037/0278-7393.31.6.1477.

Sigman, M., \& Dehaene, S. (2006). Dynamics of the central bottleneck: Dual-task and task uncertainty. PLoS Biology, 4(7), e220. https:// doi.org/10.1371/journal.pbio.0040220.

Szameitat, A. J., Lepsien, J., von Cramon, D. Y., Sterr, A., \& Schubert, T. (2006). Task-order coordination in dual-task performance and the lateral prefrontal cortex: an event-related fMRI study. $P$ sychological Research Psychologische Forschung, 70(6), 541-552. https://doi.org/10.1007/s004260050015-5.

Töllner, T., Strobach, T., Schubert, T., \& Müller, H. (2012). The effect of task order predictability in audio-visual dual task performance: Just a central capacity limitation? Frontiers in Integrative Neuroscience, 6, 75. https://doi.org/10.3389/fnint.2012.00075.

Vandierendonck, A., Liefooghe, B., \& Verbruggen, F. (2010). Task switching: Interplay of reconfiguration and interference control. Psychological Bulletin, 136(4), 601-626. https://doi.org/10.1037/ a0019791. 